\title{
El proyecto BEPS y la planeación fiscal
}

\section{The BEPS project and the tax planning}

\author{
BÁRCENAS-PUENTE, José Luis†ं* \& ANDRADE-OSEGUERA, Miguel Ángel \\ Universidad Tecnológica del Suroeste de Guanajuato. Carretera Valle de Santiago - Huamimaro Km. 1.2, 20 de \\ Noviembre, 38400 Valle de Santiago, Gto.
}

ID $1^{\text {er }}$ Autor: José Luis, Bárcenas-Puente / ORC ID: 0000-0002-1051-8861, Researcher ID Thomson: S-8603-2018, CVU CONACYT ID: 743962

ID $1^{\text {er }}$ Coautor: Miguel Ángel, Andrade-Oseguera / ORC ID: 0000-0002-7926-9162, Researcher ID Thomson: S-65862018, CVU CONACYT ID: 509374

DOI: $10.35429 / J L A .2019 .9 .3 .37 .50$

Recibido 10 de Julio, 2019; Aceptado 30 de Septiembre, 2019

\begin{abstract}
Resumen
La planeación fiscal busca, a través de la aplicación de la ley y demás fuentes del derecho; reducir, eliminar o diferir el pago de contribuciones; es, bajo este esquema, una actividad lícita que constituye un derecho para todo contribuyente. Sin embargo, la autoridad fiscal no comparte esta consideración y, al ver disminuida la recaudación a consecuencia de estas prácticas, las califica de ilícitas. Al llevarse a cabo este tipo de estrategias a gran escala, las empresas multinacionales han conseguido disminuir su carga tributaria, sobre todo en países en vías de desarrollo; al efecto, los países miembros de la OCDE y del G-20 han emprendido una serie de acciones conocidas como "Proyecto BEPS" (Base Erosion and Profit Shifting), en español Erosión de la Base y Ubicación de Utilidades. Este material pretende exponer la licitud o ilicitud de la planeación fiscal, el contenido del Proyecto BEPS y las reacciones de México al respecto; de una forma analítica, crítica y propositiva a través de las fuentes documentales disponibles, utilizando la inducción principalmente De esta forma, se intenta aportar un panorama general del tema, proporcionando elementos de juicio de los cuales el lector podrá sustentar su postura.
\end{abstract}

Licitud, Planeación, Evasión

\begin{abstract}
Tax planning seeks, through the application of the law and other sources of law; reduce, eliminate or defer the payment of contributions; under this scheme, it is a lawful activity which constitutes a right for every taxpayer. However, the tax authority does not share this consideration and see decreased revenues as a result of these practices, describes them as illegal. To take out this type of strategy on a large scale, multinational enterprises have managed to reduce their tax burden, especially in developing countries; for this purpose, members of the OECD and the G-20 countries undertaken a series of actions known as "Project BEPS" (Base Erosion and Profit Shifting), in Spanish Base Erosion and location of utilities. This material is intended to expose the legality or illegality of fiscal planning, the contents of the BEPS project and the reactions of Mexico in this regard; in an analytical, critical and purposeful way through of the documental available sourses, using induction meanly. By the way, try it give a general panorama of the theme, providing elements of judgment of wich the reader can support this position.
\end{abstract}

Legality, Planning, Evasion

Citación: BÁRCENAS-PUENTE, José Luis \& ANDRADE-OSEGUERA, Miguel Ángel. El proyecto BEPS y la planeación fiscal. Revista de Aplicaciones del Derecho. 2019. 3-9: 37-50.

\footnotetext{
*Correspondencia al Autor (Correo Electrónico: jlbarcenasp@utsoe.edu.mx)

$\dagger$ Investigador contribuyendo como primer autor.
} 


\section{Introducción}

Hace ya varios ayeres cuando en la Conferencia Magistral de Reformas Fiscales 2002 organizada por la UNAM en el Teatro de los Insurgentes de la Ciudad de México, el Mtro. Carlos Orozco Felgueres (qepd), en su intervención, hablara sobre la "productividad fiscal". En efecto, en su concepto, si el empresario busca hacer uso eficiente de sus recursos, vender más, abatir costos, producir más y mejor...¿̨por qué no buscar, de igual modo, la productividad fiscal? No basta, decía el prestigiado colega, calcular correctamente los pagos provisionales y la declaración anual de ISR...debemos hacerlo de la mejor manera posible, es decir, buscando el menor desembolso para el cliente, sin ocasionarle, evidentemente, problemas fiscales o penales posteriores. Nunca de una manera tan clara y contundente se había abordado el tema. Y no era para menos, se trata de uno de los fiscalistas más importantes del país, quien manejaba académica y profesionalmente las estrategias fiscales, como lo que son, ciencia y arte al servicio del cliente. Esta productividad de la que hablaba el maestro se logra con un paquete de estrategias englobadas en lo que conocemos como planeación fiscal. Se trata de una serie de acciones que, producto del estudio de las leyes y otras fuentes del derecho, buscan disminuir la carga tributaria, sin recurrir a actos ilícitos. Es evidente que una planeación de estas características, aun siendo un derecho legítimo, como fue expuesto por Don Carlos, no es para nada del agrado de las autoridades fiscales, quienes la catalogan como evasión fiscal.

La planeación fiscal puede llevarse a cabo en distintas dimensiones; existen desde las estrategias más sencillas hasta las más elaboradas y complejas, para lo cual se requiere un nivel de entrenamiento técnico que en muchas ocasiones invade otras ramas del derecho. Este material toma como punto de partida este concepto definiéndolo y analizándolo como ese derecho que tiene todo contribuyente a ser más eficiente en el cumplimiento de sus obligaciones fiscales; para entonces poder entender una planeación fiscal en el ámbito internacional del que México forma parte y del que organismos como la Organización para la Cooperación y el Desarrollo Económico (OCDE) y el G-20 han tomado postura para rechazar prácticas de este tipo que disminuyan la recaudación entre países.
Para ello, en consecuencia, se tratarán cuestionamientos como: ¿Cuál es la función de la OCDE y el G-20 en materia tributaria internacional?, ¿existe alguna relación entre la planeación fiscal y la regulación de precios de transferencia?, ¿qué es el Proyecto BEPS y como ayuda a combatir estas prácticas?, ¿qué avances se han logrado?, ¿qué ha hecho el fisco mexicano al respecto?

\section{La planeación fiscal, concepto y consideraciones}

Comencemos con las siguientes definiciones:

"Es la optimización de la obligación sustantiva y colateral a que está obligado el contribuyente" (Corona, 2017).

Por Planeación Fiscal, debemos entender toda aquella aplicación de estrategias que permitan reducir, eliminar o diferir la carga tributaria del contribuyente, apegándose siempre a lo establecido por las leyes, contando con el soporte documental que demuestre su licitud, procurando el menor riesgo. (Hernández, 2019).

A fin de poder analizar la primera definición, habremos de revisar el artículo 5 del Código Fiscal de la Federación, texto de donde el autor obtiene estos tipos de obligaciones fiscales, la sustantiva y la colateral: Las disposiciones fiscales que establezcan cargas a los particulares y las que señalan excepciones a las mismas, así como las que fijan las infracciones y sanciones, son de aplicación estricta. Se considera que establecen cargas a los particulares las normas que se refieren al sujeto, objeto, base, tasa o tarifa.

Las otras disposiciones fiscales se interpretarán aplicando cualquier método de interpretación jurídica. A falta de norma fiscal expresa, se aplicarán supletoriamente las disposiciones del derecho federal común cuando su aplicación no sea contraria a la naturaleza propia del derecho fiscal. (Código Fiscal de la Federación, 2019).

Cada uno de los dos párrafos transcritos nos marca precisamente la división que hace Corona de las obligaciones fiscales en sustantivas y colaterales, para lo cual existen del mismo modo disposiciones también sustantivas y colaterales; del siguiente modo:

BÁRCENAS-PUENTE, José Luis \& ANDRADEOSEGUERA, Miguel Ángel. El proyecto BEPS y la planeación fiscal. Revista de Aplicaciones del Derecho. 2019 
En el caso del primer párrafo:

Aquellas disposiciones que establecen cargas a los particulares (las que se refieren al sujeto, objeto, base, tasa o tarifa-elementos de la contribución); excepciones a las mismas; infracciones y sanciones; son de aplicación estricta. Son sustantivas.

En el caso del segundo párrafo:

"Las otras disposiciones", mismas que hablan de procedimientos para el cumplimiento de obligaciones; admiten cualquier método de interpretación jurídica. Son colaterales o adjetivas, como las llaman otros autores.

De esta manera, Corona habla de la optimización de ambas obligaciones; esto es planeación fiscal, definición que recoge la idea planteada por el maestro Orozco Felgueres, puesto que optimizar es ser eficiente, ser productivo.

La segunda definición citada nos detalla más el concepto, de donde se desprenden las siguientes ideas esenciales:

- Se trata de estrategias que permiten eliminar, reducir o diferir la carga tributaria.

- Deben apegarse a la ley.

- Debe contarse con el soporte documental que demuestre tal licitud, procurando el menor riesgo.

De estas ideas, tal vez la única que pudiera cuestionarse es la última frase, procurando el menor riesgo, puesto que si la planeación fue correctamente elaborada, no debiera existir tal riesgo, ya que se debe cuidar que todos los elementos que la componen cumplan con la ley. Es así que podemos proponer la siguiente definición, combinando las dos anteriores:

Planeación fiscal es el conjunto de estrategias que permitan la eliminación, reducción o diferimiento de la carga tributaria; con apego a la ley en sus componentes sustantivos y adjetivos. fiscal?

¿Cómo se lleva a cabo la planeación
El mismo autor Corona propone las siguientes etapas (Corona, 2017):

a) Diagnóstico fiscal (a priori y a posteriori).

b) Diseño de alternativas o rumbos de acción a seguir y valuación cuantitativa y cualitativa.

c) Determinación del costo-beneficio (evaluación).

d) Elaboración del plan de trabajo.

e) Ejecución.

f) Seguimiento, revisión por modificaciones a las leyes.

De cual podemos comentar lo siguiente:

En el diagnóstico fiscal debemos basarnos en el tipo de actividad que realiza el contribuyente, el régimen fiscal al que pertenece y las obligaciones que emanan del mismo; con ello tenemos el panorama general que servirá de punto de partida.

Con este expediente documental y el diagnóstico que se ha elaborado, se procede a diseñar las acciones a seguir (estrategias).

Se define posteriormente la relación costo-beneficio, a la luz de lo que el contribuyente pretende y lo que se puede lograr.

Ya evaluados los objetivos, se elabora el plan de trabajo.

En la etapa de ejecución de redactan los convenios o contratos necesarios que sirvan de soporte documental.

Esta última etapa de seguimiento es imprescindible en la dinámica del derecho fiscal, lo que puede ser bueno hoy, puede no serlo mañana.

\section{Evasión fiscal, elusión fiscal, defraudación fiscal y planeación fiscal.}

Ya que se ha planteado el quehacer de la planeación fiscal, es conveniente discernir sobre la evasión, elusión y defraudación, para tener claro ahora lo que no es la planeación fiscal.

BÁRCENAS-PUENTE, José Luis \& ANDRADEOSEGUERA, Miguel Ángel. El proyecto BEPS y la planeación fiscal. Revista de Aplicaciones del Derecho. 2019 
Creemos que son tres términos diferentes, la evasión está relacionada con la omisión del pago no apegada a derecho y la elusión con el hecho de evitar las responsabilidades fiscales por medio de la maquinación dolosa; en cambio, la planeación fiscal es el esfuerzo por optimizar la carga tributaria ceñida estrictamente a derecho y ocupando los recursos de la empresa. (Corona, 2017).

Esta cita sintetiza acertadamente los conceptos evasión y elusión, contrastando con la planeación fiscal.

Coincide en lo sustancial esta definición de evasión fiscal:

"Evasión Fiscal, es la disminución o no realización del pago de una contribución por parte del sujeto pasivo quien se encuentra jurídicamente obligado a pagarlo mediante conductas fraudulentas u omisivas violando las disposiciones legales." (Hernández, 2019).

Y por lo que se refiere a la elusión fiscal:

"Elusión Fiscal, se presenta cuando el contribuyente realiza una interpretación conceptual distinta a la intención del legislador buscando obtener un beneficio económico, aprovechando las fracturas de la ley, eligiendo los caminos que le generen un beneficio mayor”. (Hernández, 2019).

Concretando, la evasión fiscal se refiere a la omisión del pago violando la ley y la elusión fiscal utiliza la simulación (aparentar una situación jurídica u operación, siendo en realidad otra) para obtener un beneficio. La defraudación, en cambio, resulta ser una combinación de ambas, al ser definida por el Código Fiscal de la Federación de la siguiente forma:

“Artículo 108.- Comete el delito de defraudación fiscal quien con uso de engaños o aprovechamiento de errores, omita total $\mathrm{o}$ parcialmente el pago de alguna contribución u obtenga un beneficio indebido con perjuicio del fisco federal. (...)" (Código Fiscal de la Federación, 2019).
El primer párrafo de esta disposición nos define la defraudación fiscal, estableciendo que ésta consiste en el uso de engaños o aprovechamiento de errores para omitir el pago y así obtener un beneficio; de hecho, es el único concepto de los que se ventilan en este apartado, que conlleva una pena corporal en nuestro marco jurídico fiscal.

Para acotar aún más el delito de defraudación fiscal, el propio artículo 108 en comento, dispone:

El delito de defraudación fiscal y los previstos en el artículo 109 de este Código, serán calificados cuando se originen por (Código Fiscal de la Federación, 2019):

a).- Usar documentos falsos.

b).- Omitir reiteradamente la expedición de comprobantes por las actividades que se realicen, siempre que las disposiciones fiscales establezcan la obligación de expedirlos. Se entiende que existe una conducta reiterada cuando durante un período de cinco años el contribuyente haya sido sancionado por esa conducta la segunda o posteriores veces.

c).- Manifestar datos falsos para obtener de la autoridad fiscal la devolución de contribuciones que no le correspondan.

d).- No llevar los sistemas o registros contables a que se esté obligado conforme a las disposiciones fiscales o asentar datos falsos en dichos sistemas o registros.

e) Omitir contribuciones retenidas, recaudadas o trasladadas.

f) Manifestar datos falsos para realizar la compensación de contribuciones que no le correspondan.

g) Utilizar datos falsos para acreditar o disminuir contribuciones.

h) Declarar pérdidas fiscales inexistentes.

Por su parte, el artículo 109 del mismo Código dispone: 
Artículo 109.- Será sancionado con las mismas penas del delito de defraudación fiscal, quien (Código Fiscal de la Federación, 2019):

I. Consigne en las declaraciones que presente para los efectos fiscales, deducciones falsas o ingresos acumulables menores a los realmente obtenidos o valor de actos o actividades menores a los realmente obtenidos o realizados o determinados conforme a las leyes. En la misma forma será sancionada aquella persona física que perciba ingresos acumulables, cuando realice en un ejercicio fiscal erogaciones superiores a los ingresos declarados en el propio ejercicio y no compruebe a la autoridad fiscal el origen de la discrepancia en los plazos y conforme al procedimiento establecido en la Ley del Impuesto sobre la Renta.

II. Omita enterar a las autoridades fiscales, dentro del plazo que la ley establezca, las cantidades que por concepto de contribuciones hubiere retenido $\mathrm{o}$ recaudado.

III. Se beneficie sin derecho de un subsidio o estímulo fiscal.

IV. Simule uno o más actos o contratos obteniendo un beneficio indebido con perjuicio del fisco federal.

V. Sea responsable por omitir presentar por más de doce meses las declaraciones que tengan carácter de definitivas, así como las de un ejercicio fiscal que exijan las leyes fiscales, dejando de pagar la contribución correspondiente.

\section{VI. (Se deroga)}

\section{VII. (Se deroga)}

VIII. Darle efectos fiscales a los comprobantes digitales cuando no reúnan los requisitos de los artículos 29 y 29-A de este Código.

Este listado de prácticas le da sustento al delito de defraudación fiscal, para su mejor comprensión y ayuda a distinguir que la planeación fiscal no contempla ninguna de ellas, lo que confirma su naturaleza distinta.

\section{La planeación fiscal por medio de precios de transferencia entre partes relacionadas residentes en el extranjero.}

Como se dijo, la planeación fiscal puede llevarse a cabo a distintos tipos de contribuyentes, diferentes operaciones y regímenes fiscales; igual a un RIF (Régimen de Incorporación Fiscal), que a una persona moral del Título II de la LISR o incluso un grupo de empresas nacional o extranjero, considerando así una planeación a gran escala.

Sin ser éste el único medio por el cual se puede diseñar una planeación fiscal entre países; se analizará el caso de los precios de transferencia entre partes relacionadas residentes en el extranjero para exponer y comprender la naturaleza del Proyecto BEPS.

Para tal efecto, es conveniente entrar en contexto para posteriormente ir al grano con este apartado. Así, es importante establecer lo siguiente:

- El 18 de mayo de 1994, México se convirtió en el miembro 25 de la Organización para la Cooperación y el Desarrollo Económico (OCDE). (Organización para la Cooperación y el Desarrollo Económico, 2018).

- A raíz de tal membresía, la OCDE ha trazado directrices en materia económica, cultural, social y educativa hacia nuestro país. Tal es el caso de la inclusión, a partir de 1997, de la figura precios de transferencia en la Ley del Impuesto sobre la Renta. (Bárcenas, 2019).

- De esta forma, se incluyó en el entonces artículo 64-A de la LISR, (ahora 179), el concepto partes relacionadas:

Se considera que dos o más empresas son partes relacionadas, cuando una participa de manera directa o indirecta en la administración, control o capital de la otra, o cuando una persona o grupo de personas participe directa o indirectamente en la administración, control o capital de dichas personas. (Ley del Impuesto sobre la Renta, 2019). 
- Asimismo, el artículo 65 de la misma ley (ahora 180), establece seis métodos para comprobar que las operaciones con partes relacionadas (cobro de intereses, regalías, prestación de servicios, compra de materia prima, etc.), fueron pactadas a precio de mercado; para ello, se comparan operaciones $\mathrm{y}$ precios pactados con partes no relacionadas. Esto, mediante un documento denominado Estudio de Precios de Transferencia (Bárcenas, 2019).

- La regulación original de tipo internacional en esta materia, proviene de los Lineamientos guía para precios de transferencia, emitidos por la OCDE, mismos que se aplican supletoriamente a lo que establece la regulación mexicana. (Bárcenas, Pasado y presente de los precios de transferencia, 2019).

- De la aplicación de uno o más de uno de los métodos establecidos, se obtiene en dicho estudio, un rango intercuartílico en el que debe ubicarse el precio al que se pactaron las operaciones; de ser así, se comprueba entonces el precio de mercado. (Bárcenas, 2019).

¿Se puede realizar planeación fiscal mediante precios de transferencia?

Definitivamente sí. ¿Cómo hacerlo? Mediante la determinación del rango intercuartílico que ya se explicó. Es decir, si conocemos un precio o nivel de utilidades mínimo y máximo, estamos en la aptitud de manejar los resultados de la empresa sin caer en problemas de precios de mercado, puesto que la Ley permite el uso de un rango dentro del cual moverse. (Bárcenas, Precios de transferencia entre partes relacionadas: Panorama general en la Ley del Impuesto sobre la Renta y oportunidades de planeación fiscal., 2008).

¿Qué ocurriría si no se encontrase regulado el precio de mercado en las operaciones que realizan las partes relacionadas?

Ello se prestaría a que se manipularan utilidades a través de los precios pactados, provocando la fuga de las mismas hacia otro país y con ello el menoscabo en el pago de ISR.
Esta es precisamente la razón por la cual la OCDE, en adición al G-20 ha implementado el proyecto BEPS, como un mecanismo para contrarrestar acciones de planeación fiscal que finalmente repercuten en la disminución del pago de ISR entre países.

\section{EI Proyecto BEPS}

A esta planeación fiscal a gran escala, se le ha llamado BEPS, definido por la OCDE de la siguiente manera:

BEPS hace referencia a la erosión de la base imponible y al traslado de beneficios propiciados por la existencia de lagunas o mecanismos no deseados entre los distintos sistemas impositivos nacionales de los que pueden servirse las empresas multinacionales $(\mathrm{EMN})$, con el fin de hacer "desaparecer" beneficios a efectos fiscales, o bien de trasladar beneficios hacia ubicaciones donde existe escasa o nula actividad real, si bien goza de una débil imposición, derivando en escasa o nula renta sobre sociedades. A tenor de la creciente movilidad del capital y de activos tales como la propiedad intelectual, así como de los nuevos modelos de negocio del siglo XXI, BEPS se ha convertido en un serio problema. (Organización para la Cooperación y el Desarrollo Económico, 2019).

En efecto, BEPS (por sus siglas en inglés) es el nombre que se le ha dado a la Erosión de la Base y Ubicación de Utilidades, traducción literal; que en otras palabras podríamos considerar como la disminución de la base gravable en las empresas a causa del traslado de utilidades de un país a otro. La OCDE ha detectado que se transfiere capital y activos a países de débil imposición, convirtiéndose en un serio problema.

\section{¿Cómo surge BEPS?}

La recaudación del impuesto sobre sociedades se efectúa a nivel nacional. En los casos de actividades económicas transnacionales, la interacción entre distintos sistemas impositivos nacionales puede derivar en la imposición por parte de más de una jurisdicción, o doble imposición. Las actuales normas impositivas internacionales fueron confeccionadas para evitar tal situación. Sin embargo, estas mismas normas han facilitado, en algunos casos, el caso contrario, por ejemplo, la doble no imposición.

BÁRCENAS-PUENTE, José Luis \& ANDRADEOSEGUERA, Miguel Ángel. El proyecto BEPS y la planeación fiscal. Revista de Aplicaciones del Derecho. 2019 
A su vez, la interacción entre los sistemas impositivos nacionales puede provocar resquicios o lagunas que impiden la imposición de beneficios en una ubicación específica (renta apátrida). (Organización para la Cooperación y el Desarrollo Económico, 2019)

La OCDE detecta dos principales fuentes que han propiciado BEPS, de acuerdo a esto:

- Tratados para evitar la doble imposición, cuya aplicación (o su redacción) se ha desvirtuado; llegando a propiciar la doble no tributación, afectando así los dos países involucrados.

- Interacción entre sistemas fiscales cuyos resquicios o lagunas (omisiones) pueden provocar la falta de pago del impuesto en un país específico (ISR sin patria).

\section{¿Qué tan grave es BEPS?}

Los problemas de BEPS afectan de igual manera tanto a países desarrollados como a países en desarrollo: según los datos actuales, se estima la presencia de BEPS en un 4\% - 10\% de la recaudación del impuesto sobre sociedades (CIT), lo que supone alrededor de 100-240 mil millones de dólares estadounidenses anuales.

Los países en desarrollo poseen un alto grado de dependencia sobre los ingresos derivados de la renta de sociedades multinacionales en tanto que porcentaje de ingresos tributarios, mientras que su impacto en los países desarrollados en términos absolutos es significativamente superior. Es decir, del total de la afectación, la correspondiente a los países en desarrollo es relativa al total de ingresos tributarios, dada la dependencia de la recaudación proveniente de empresas multinacionales. En tanto, para los países desarrollados dicho perjuicio se presenta en mayor medida en términos absolutos.

En realidad, ¿BEPS es ilegal?

Algunas estrategias de planificación impositiva de BEPS podrían ser ilegales, pero la mayoría no lo son.
Las disposiciones de BEPS se benefician habitualmente de las normas obsoletas de un modelo económico cimentado en medidas pretéritas y no en la economía globalizada del siglo XXI, caracterizada por la creciente importancia de intangibles, como la propiedad intelectual. Por este motivo, los países del G-20 y de la OCDE, junto con un amplio número de países no miembros -países desarrollados, emergentes y en desarrollo- han decidido colaborar conjuntamente con la finalidad de modernizar las normas impositivas internacionales para limitar los problemas de BEPS. (Organización para la Cooperación y el Desarrollo Económico, 2019).

En esta aportación, la OCDE marca una postura diferente a la autoridad fiscal mexicana respecto de la planeación fiscal. Se ha dicho que, desde el panorama presentado en este material, la planeación fiscal puede ser a gran escala, y eso es BEPS, un conjunto de estrategias que hacen uso del marco jurídico existente para eliminar, disminuir o diferir la carga tributaria, tal como se ha analizado. Sin embargo, como también se ha expuesto, para la autoridad fiscal mexicana esta concepción de planeación fiscal es inválida, fraudulenta e ilegal. La OCDE por el contrario, acepta que existen estrategias BEPS que no son ilegales, que es mera planeación; menciona además una fuente más de BEPS: Las leyes obsoletas que no han podido seguir el ritmo cambiante de la globalización, por ejemplo, tratándose de la propiedad intelectual.

¿Por qué BEPS llama la atención en la actualidad?

La crisis económica mundial ha restringido las finanzas públicas, obligando a los gobiernos a efectuar recortes en sus gastos y servicios, o bien a elevar sus impuestos para aumentar sus ingresos. Ante este panorama económico, los problemas de BEPS han supuesto un importante menoscabo al buen funcionamiento del sistema impositivo. Tanto los contribuyentes a título individual como las empresas nacionales soportan una mayor carga impositiva que las empresas internacionales que consiguen tributar a un tipo impositivo bajo o nulo. 
Las propias empresas multinacionales (EMN) han de hacer frente a un riesgo importante para su reputación, dado el interés que suscita el ámbito fiscal empresarial, cada vez que las empresas que operan en mercados internos tienen dificultades a la hora de competir con las multinacionales, que cuentan con recursos para trasladar sus beneficios más allá de sus fronteras para eludir o reducir sus impuestos. De esta forma, los gobiernos perciben ingresos inferiores. (Organización para la Cooperación y el Desarrollo Económico, 2019). Es la crisis económica mundial la que ha propiciado que se enciendan las alarmas hacia BEPS. En relación a lo que menciona la cita, en el caso del sistema fiscal mexicano; el Servicio de Administración Tributaria prefiere fiscalizar y perseguir a contribuyentes del RIF y personas morales de mediana capacidad, e incluso asalariados, que a empresas multinacionales, tal es el caso de la escasa o nula revisión al cumplimiento de obligaciones en materia de precios de transferencia. (Bárcenas, Pasado y presente de los precios de transferencia, 2019).

¿Qué solución se ha planteado?,¿Qué es el Proyecto o Paquete BEPS?

El paquete BEPS de la OCDE/G-20 publicado en octubre de 2015 contiene medidas para mejorar la coherencia de los estándares impositivos internacionales, reforzar su focalización en la sustancia económica y garantizar un entorno fiscal de mayor transparencia. Ello implica cambios en materia de convenios tributarios bilaterales, incluyendo: un estándar mínimo con el fin de prevenir la búsqueda del tratado más favorable; la revisión de las normas sobre el traslado de beneficios, que determinan el tratamiento fiscal de las transacciones intragrupo; el enfoque sobre el sustrato de las transacciones en lugar de su forma legal; la actualización del marco de evaluación de los efectos potencialmente perniciosos de los regímenes preferenciales introducidos por los gobiernos, haciendo especial hincapié en el régimen y estándares impositivos aplicados a la propiedad intelectual; las medidas legislativas nacionales para hacer frente a BEPS. (Organización para la Cooperación y el Desarrollo Económico, 2019).

¿Cuáles son esas medidas que incluye el Proyecto BEPS?
Acción 1 - Abordar los retos de la economía digital para la imposición.

Acción 2 - Neutralizar los efectos de los mecanismos híbridos.

Acción 3 - Refuerzo de la normativa sobre CFC.

Acción 4 - Limitar la erosión de la base imponible por vía de deducciones en el interés y otros pagos financieros.

Acción 5 - Combatir las prácticas tributarias perniciosas, teniendo en cuenta la transparencia y la sustancia.

Acción 6 - Impedir la utilización abusiva de convenios.

Acción 7 - Impedir la elusión artificiosa del estatuto de EP.

Acciones 8-10 - Asegurar que los resultados de los precios de transferencia están en línea con la creación de valor. de BEPS.

Acción 11 - Evaluación y seguimiento

Acción 12 - Exigir a los contribuyentes que revelen sus mecanismos de planificación fiscal agresiva.

Acción $13-$ Reexaminar la documentación sobre precios de transferencia.

Acción 14 - Hacer más efectivos los mecanismos de resolución de controversias.

Acción 15 - Desarrollar un instrumento multilateral (Organización para la Cooperación y el Desarrollo Económico, 2015).

Por lo que respecta a la Acción 1; básicamente consisten en gravar con IVA las operaciones de comercio electrónico, recaudándolo en el país donde se encuentra el consumidor.

La Acción 2 establece lo siguiente:

Se ha desarrollado una metodología común que facilitará la convergencia de las prácticas nacionales a través de normas internas y convencionales dirigidas a neutralizar tales mecanismos.

BÁRCENAS-PUENTE, José Luis \& ANDRADEOSEGUERA, Miguel Ángel. El proyecto BEPS y la planeación fiscal. Revista de Aplicaciones del Derecho. 2019 
Esta metodología contribuirá, por un lado, a prevenir la doble no imposición mediante la eliminación de los beneficios fiscales derivados de dichos desajustes y, por otro lado, a poner fin a las costosas deducciones múltiples por un único pago, a las deducciones en un país sin el correspondiente gravamen en el otro y a la generación de múltiples créditos fiscales por un único impuesto pagado en el extranjero. (Organización para la Cooperación y el Desarrollo Económico, 2015).

En el caso de México, ya desde 2014 se atendió esta medida, misma que se contempla en el segundo párrafo del artículo 4 de la Ley del Impuesto sobre la Renta, de la siguiente manera:

Además de lo previsto en el párrafo anterior, tratándose de operaciones entre partes relacionadas, las autoridades fiscales podrán solicitar al contribuyente residente en el extranjero que acredite la existencia de una doble tributación jurídica, a través de una manifestación bajo protesta de decir verdad firmada por su representante legal, en la que expresamente señale que los ingresos sujetos a imposición en México y respecto de los cuales se pretendan aplicar los beneficios del tratado para evitar la doble tributación, también se encuentran gravados en su país de residencia, para lo cual deberá indicar las disposiciones jurídicas aplicables, así como aquella documentación que el contribuyente considere necesaria para tales efectos. (Ley del Impuesto sobre la Renta, 2019).

La OCDE llama mecanismos híbridos aquellos donde un contribuyente no tiene afectación por la doble tributación y aun así se somete a los beneficios de un tratado; como busca evitar el párrafo que se ha reproducido.

La Acción 3, referente a las normas sobre CFC (empresas controladas en el extranjero, por sus siglas en inglés), busca impedir que se traslades utilidades a subsidiarias ubicadas en paraísos fiscales.

La Acción 4 se refiere a las deducciones por concepto de intereses provenientes de deudas entre las empresas del grupo, vigilando que los capitales tengan una relación directa con sus actividades económicas.
En la Acción 5, el proyecto busca combatir que las empresas se trasladen a tal o cual ubicación sin tener una razón de negocios que lo sustente.

Por lo que respecta a la Acción 6, se pretende modificar el texto del Convenio Modelo para Evitar la Doble Tributación, del cual se basan todos los Tratados, con el fin de "poner candados" a una aplicación de los mismos que provoque la ilegal falta de pago del impuesto.

La Acción 7 está claramente expuesta en las siguientes líneas:

Los convenios fiscales prevén que los beneficios empresariales de una entidad no residente sean gravables en un estado sólo en la medida en que dicha entidad tenga un establecimiento permanente en dicho estado al que se le puedan atribuir beneficios. Por lo tanto, la definición de este concepto resulta crucial al momento de determinar si la entidad no residente debe tributar en tal estado. El informe en cuestión respecto de esta acción 7 efectúa cambios a este concepto los cuales, hacen frente a las técnicas empleadas para esquivar el nexo fiscal, mediante por ejemplo, el reemplazo de los distribuidores por mecanismos de comisionistas o la fragmentación artificial de las actividades. (Instituto Mexicano de Contadores Públicos, AC, 2016).

Las Acciones 8 a 10 comparten el mismo concepto, precios de transferencia; desglosando cada una, tenemos lo siguiente:

- La Acción 8 se refiere a las operaciones que involucran activos intangibles, mismas que por lo general, según se ha detectado, propician la erosión de la base imponible.

- La Acción 9, en el mismo sentido, pero respecto de la contratación de seguros.

- La Acción 10, asimismo, pero en el caso de pagos diversos entre las partes relacionadas.

La Acción 11 busca mantener actualizado el control de los indicadores BEPS detectados, para dar seguimiento y evaluar frecuentemente. 
La Acción 12 se expone de la siguiente manera:

Según este estudio, uno de los desafíos fundamentales a los que se enfrentan las administraciones tributarias de todo el mundo es la falta de información puntual y completa sobre las estrategias fiscales agresivas. El informe de esta acción establece un marco modular de guías basadas en mejores prácticas para su uso para aquellos países que carezcan de normas de declaración obligatoria y deseen idear un régimen que satisfaga su necesidad de obtener información anticipada sobre las estrategias de planificación fiscal agresiva o abusiva y sus usuarios. Igualmente, el marco propuesto está dirigido para aquellos países que cuenten con regímenes de declaración obligatoria pero deseen mejorar su eficacia. (Instituto Mexicano de Contadores Públicos, AC, 2016).

Actualmente, México no cuenta aún con este tipo de declaraciones informativas. Sin embargo, de última hora, al cierre de este material se ha difundido una iniciativa presidencial al Congreso mexicano que la incluye, como se revisará en líneas más adelante.

La Acción 13 considera tres rubros en los precios de transferencia:

- La documentación comprobatoria que sobre precios de transferencia deba entregarse a la autoridad fiscal. Aquí cabe señalar que en México esta documentación solamente se entrega a solicitud de la propia autoridad.

- Documentación sobre las operaciones realizadas en el mercado local.

- Informe, país por país, de los ingresos y utilidades obtenidos.

La Acción 14 pretende dar mayor certidumbre jurídica a los contribuyentes mediante una solución de controversias más oportuna.

Para cristalizar el documento que plantea la Acción 15, se cuenta con los países miembros de la OCDE, del G-20, e incluso algunos no miembros.
El Proyecto nació a fines de 2015 y se busca que para 2020 tenga una sólida estructura (EY Abogados, 2019).

\section{Medidas de la autoridad fiscal mexicana respecto del Proyecto BEPS}

En nuestro país, el derecho fiscal cuenta, además de las fuentes del derecho conocidas, siendo la Ley la principal de ellas, con otras dos opciones de regulación, de naturaleza administrativa, puesto que son emitidas por la propia autoridad fiscal, éstas son:

- Reglas de miscelánea, con fundamento legal en el artículo 33, fracción I, inciso g) del Código Fiscal de la Federación. Sirven para facilitar el cumplimiento de las obligaciones fiscales y se concretan a procedimientos, trámites, avisos, etc. Por disposición expresa de su fundamento, si se refieren a los elementos de la contribución, no generarán cargas adicionales a las establecidas en Ley. (Aquí se encuentran muchas de las disposiciones que Corona, citado en apartados anteriores, llama "colaterales").

- Criterios no vinculativos, con fundamento legal en el artículo 33, fracción I, inciso h) del Código Fiscal de la Federación. Sirven para que el contribuyente conozca aquellas prácticas que, sin estar expresamente prohibidas en la Ley, la autoridad fiscal las considera "indebidas". Se les llama "no vinculativos" porque su observancia no es obligatoria para el contribuyente.

Hasta ahora, dentro de estos "criterios", vigentes para 2019, se encuentra uno que menciona cierta aclaración o restricción respecto del establecimiento permanente, tratando así de coadyuvar con lo dispuesto en la Acción 7 del Proyecto BEPS, en los siguientes términos:

1/ISR/NV Establecimiento permanente.

Conforme al artículo 1, fracción II de la Ley del ISR, las personas físicas y las morales están obligadas al pago del ISR cuando se trate de residentes en el extranjero que tengan un establecimiento permanente en el país, respecto de los ingresos atribuibles a dicho establecimiento permanente. 
Conforme al artículo 2, segundo párrafo de la Ley del ISR, el Artículo 5, de los tratados para evitar la doble tributación que México tiene en vigor y los párrafos 31 a 35 de los Comentarios al artículo 5 del "Modelo de Convenio Tributario sobre la Renta y el Patrimonio", a que hace referencia la recomendación adoptada por el Consejo de la OCDE el 23 de octubre de 1997, tal como fueron publicados después de la adopción por dicho Consejo de la novena actualización o de aquella que la sustituya, se considera que el residente en el extranjero tiene un establecimiento permanente en el país cuando se encuentre vinculado en los términos del derecho común con los actos que efectúe el agente dependiente por cuenta de él, con un residente en México.

Por lo anterior, se considera que realiza una práctica fiscal indebida:

I. El residente en el extranjero que no pague el ISR en México al considerar que no tiene un establecimiento permanente en el país cuando se encuentre vinculado en los términos del derecho común con los actos que efectúe el agente dependiente por cuenta de él, con un residente en México.

II. Quien asesore, aconseje, preste servicios o participe en la realización o la implementación de la práctica anterior. (Secretaría de Hacienda y Crédito Público, 2019).

\section{Disposiciones contenidas en la Iniciativa de Reforma Fiscal 2020 enviada al Congreso por el Ejecutivo Federal que responden a las acciones del Proyecto BEPS}

Se encuentra en revisión por el Congreso el llamado Paquete Económico 2020, enviado por el Ejecutivo el 8 de septiembre de 2019, en cuyo Anexo D, se encuentra la Iniciativa de Reforma Fiscal. De las propuestas, aquellas que responden a las acciones del Proyecto BEPS, de las cuales se transcribe un extracto, son:

1. Actualización del concepto de establecimiento permanente por virtud de las recomendaciones de la acción 7 del Proyecto BEPS. De la siguiente manera:
- Establecer que cuando un residente en el extranjero actúe en el país a través de una persona distinta de un agente independiente, se considerará que el mismo tiene un establecimiento permanente en el país si dicha persona concluye habitualmente contratos o desempeña habitualmente el rol principal en la conclusión de contratos celebrados por el residente en el extranjero y estos se celebran a nombre o por cuenta del residente en el extranjero; prevén la enajenación de los derechos de propiedad, o del uso o goce temporal de un bien que posea el residente en el extranjero o sobre el cual tenga el derecho del uso o goce temporal; u obligan al residente en el extranjero a prestar un servicio.

- Señalar que se presume que una persona física o moral no es un agente independiente, cuando actúe exclusiva o casi exclusivamente por cuenta de residentes en el extranjero que sean sus partes relacionadas.

- Mencionar expresamente que las actividades señaladas en el artículo 3 de la Ley del ISR son excepciones a la constitución de establecimiento permanente cuando tengan la condición de carácter preparatorio o auxiliar.

- Incorporar una disposición con el objetivo de evitar que un residente en el extranjero o un grupo de partes relacionadas fragmenten una operación de negocios cohesiva en varias operaciones menores para argumentar que cada una encuadra en las excepciones de actividades con carácter preparatorio $\mathrm{o}$ auxiliar.

2. Combate a los mecanismos híbridos.

En el caso de recomendaciones para mejorar la legislación doméstica, se propone a esa Soberanía incluir un último párrafo en el artículo 5 de la Ley del ISR, para efectos de negar el acreditamiento indirecto cuando el pago del dividendo o utilidad distribuible haya sido deducible para el pagador.

También se propone incluir un supuesto con el fin de negar el acreditamiento directo, cuando el impuesto en cuestión también sea acreditable en otro país o jurisdicción. 
Lo dispuesto anteriormente no es aplicable cuando la razón por la cual se acreditó en el otro país o jurisdicción, fue por motivo de un acreditamiento indirecto. También se exceptúa de esta regla, cuando los ingresos que dieron motivo al pago del impuesto también hayan sido acumulados en el otro país o jurisdicción. Adicionalmente, se fortalece el régimen actual respecto a los ingresos generados a través de entidades extranjeras o figuras jurídicas transparentes, por motivo de la inclusión del Artículo 4-B propuesto. Por otra parte, se propone modificar la fracción XXIX del artículo 28 de la Ley del ISR para ajustar lo señalado en el mismo con lo recomendado por el citado Reporte Final. En este sentido, el cambio que se propone significa ampliar el número de supuestos en algunos casos y restringirlo en otros. También se establecen una serie de reglas adicionales para determinar el monto no deducible.

3. Pagos realizados a entidades extranjeras transparentes fiscales y figuras jurídicas extranjeras.

(...) esta decisión es acorde a la política fiscal internacional plasmada en los convenios para evitar la doble imposición celebrados por México. Estos convenios solo aplican a personas que sean residentes de uno de los Estados contratantes. Una entidad extranjera fiscalmente transparente para un Estado Contratante, no puede considerarse como residente en dicho Estado. Por consiguiente, no cumple con este requisito indispensable para obtener los beneficios de los Convenios. Por tal motivo, la política fiscal internacional de México en la aplicación de dichos tratados es no reconocer la transparencia fiscal, salvo que exista una disposición expresa en el mismo convenio que así lo permita. Esto es acorde a las observaciones que realizó México al Modelo OCDE vigente hasta 2014 (Párrafo 27.1 de los Comentarios al Artículo 1 y Párrafo 26.1 de los Comentarios al Artículo 4), mismas que ya no se tuvieron que realizar al Modelo OCDE vigente a partir de 2017 porque éste contiene una disposición expresa y elimina los comentarios sobre los cuales se hicieron las observaciones. Por esta razón, el artículo 4-A propuesto señala expresamente que dicha disposición no será aplicable a los tratados para evitar la doble imposición.
4. Ingresos obtenidos por residentes en México o establecimientos permanentes en territorio nacional, a través de entidades extranjeras transparentes y figuras jurídicas extranjeras.

(...) se somete a esa Soberanía una propuesta para adicionar un artículo 4-B en el Título de Disposiciones Generales de la Ley del ISR. Como ya se señaló, agregar esta disposición en el referido Título de la Ley del ISR permite evitar una confusión principalmente entre ingresos generados a través de entidades extranjeras y figuras jurídicas transparentes, e ingresos generados a través de entidades extranjeras que estén sujetos a regímenes fiscales preferentes. También es importante señalar que conforme a las recomendaciones del Reporte Final de la Acción 2 del Proyecto BEPS, una legislación extranjera puede negar la deducción de pagos realizados a entidades extranjeras transparentes, cuando los socios o accionistas no acumulen dicho ingreso como un "ingreso ordinario". Por consiguiente, para evitar que legislaciones extranjeras nieguen la deducción de pagos a entidades extranjeras transparentes en las que tengan participación un residente mexicano o establecimiento permanente ubicado en territorio nacional, es necesario que dichos ingresos estén sujetos a las disposiciones generales de la Ley del ISR. De lo contrario, dichos residentes mexicanos o establecimientos permanentes podrán verse afectados indirectamente porque se puede negar en el extranjero la deducción del pago que reciben las entidades extranjeras en las que tengan participación.

5. Ingresos sujetos a regímenes fiscales preferentes que obtienen entidades extranjeras controladas.

La propuesta presentada a esa Soberanía tiene dos finalidades: 1) atender gran parte de las recomendaciones del Reporte Final de la Acción 3 del Proyecto BEPS con el fin de fortalecer la aplicación de este Capítulo; y 2) aclarar ciertas disposiciones que han generado problemas en la implementación del mismo.

\section{Limitación a la deducción de intereses.}

7. Propuesta de tratamiento a los servicios digitales proporcionados por residentes en el extranjero sin establecimiento en México. 
(...) se propone establecer en el artículo 16 de la Ley del IVA que tratándose de los servicios digitales que sean prestados por residentes en el extranjero sin establecimiento en México, se considera que el servicio se presta en territorio nacional cuando el receptor del servicio se encuentre en el territorio mencionado. Lo anterior encuentra plena justificación, ya que si bien es cierto el emisor no es residente en México y tampoco tiene establecimiento en él, el servicio digital se proporciona a un receptor ubicado en territorio nacional y las contraprestaciones que obtiene tienen su origen en México.

\section{Revelación de esquemas reportables.}

En este sentido, se propone que los asesores fiscales sean los obligados principales a revelar los esquemas reportables, entendiendo por esquema reportable, cualquiera que pueda generar, directa o indirectamente, la obtención de un beneficio fiscal en México y tenga alguna de las características identificadas como áreas de riesgo. Es importante aclarar que estos requisitos deben cumplirse en conjunto, es decir, no basta con que se obtenga un beneficio fiscal en México para que un esquema se considere reportable, sino que debe tener alguna de las características específicas previstas en las disposiciones que aquí se proponen. (Cámara de Diputados, 2019).

Esta última propuesta, realmente deja sin palabras a la Contaduría Pública en su conjunto; en términos simples, ¡el Ejecutivo propone delatar a los clientes!, desvirtuando la Acción 12 del Proyecto BEPS.

\section{Conclusiones}

Se puede concluir lo siguiente:

a) La planeación fiscal, a diferencia de la evasión, la elusión y la defraudación; se basa en el análisis de la situación de cada contribuyente y el estudio de las fuentes del derecho para eliminar, reducir o diferir la carga tributaria, logrando así la productividad fiscal.

b) Esta planeación fiscal, llevada a cabo a gran escala, ha ocasionado que la recaudación internacional disminuya, prendiendo los focos rojos a organismos como la OCDE y el G-20. c) Para combatir tales prácticas, a lo que se ha llamado BEPS; estos organismos han diseñado un plan llamado Proyecto BEPS, que consta de 15 acciones definidas.

d) Un factor clave en BEPS ha sido el tema de precios de transferencia entre partes relacionadas. Figura jurídica en la que nuestro país, aun después de 22 años de su inclusión en la legislación fiscal, se encuentra en pañales.

e) Hasta 2019, la respuesta de México en contribuir al Proyecto BEPS ha sido modesta, acorde a lo expresado en el numeral anterior.

f) Para 2020, se proponen de parte del Ejecutivo 8 medidas que responden a algunas acciones del Proyecto BEPS; siendo la que corresponde a la revelación de parte de los asesores fiscales, de prácticas "de riesgo" (reportables) de los contribuyentes; la que sin duda inquieta de manera importante a la profesión contable.

g) Si tomamos en cuenta que el partido político en el poder es precisamente el que tiene mayoría en el Congreso; se puede pronosticar que todas o la mayoría de las propuestas sean aprobadas; con lo que se pueden advertir los siguientes problemas:

- Más incertidumbre jurídica, al tratarse de temas que la autoridad fiscal ha demostrado no conocer.

- Hoy más que nunca podemos hablar de un terrorismo fiscal, al equipar conductas de manera desproporcionada.

- Lejos de incrementar la recaudación, se vislumbran afectaciones en los negocios.

\section{Referencias}

Bárcenas, J. L. (2008). Precios de transferencia entre partes relacionadas: Panorama general en la Ley del Impuesto sobre la Renta y oportunidades de planeación fiscal. Diversidades, 11-14.

Bárcenas, J. L. (2019). Pasado y presente de los precios de transferencia. Revista de Desarrollo Económico (ECORFAN), 55-68. 
Cámara de Diputados. (8 de septiembre de 2019). Gaceta Parlamentaria. Obtenido de www.diputados.gob.mx

Código Fiscal de la Federación. (2019). México: Tax Editores.

Corona, J. (2017). 100 beneficios fiscales 2017. México: Gasca.

EY Abogados. (10 de enero de 2019). EY Abogados. Alerta informativa. Obtenido de ey.com/es

Hernández, E. (3 de julio de 2019). Planeación fiscal (casos prácticos). (A. Colegio de Contadores Públicos de León, Recopilador) León, Guanajuato, México: Sin editorial.

Instituto Mexicano de Contadores Públicos, AC. (4 de enero de 2016). Fiscoactualidades. Obtenido de www.imcp.org.mx

Ley del Impuesto sobre la Renta. (2019). México: Tax Editores.

Organización para la Cooperación y el Desarrollo Económico. (2 de octubre de 2015). Nota explicativa. Proyecto OCDE/G-20 sobre la Erosión de la Base Imponible y el Traslado de Beneficios. Obtenido de www.oecd.org/ctp/beps-2015-

notaexplicativa.pdf

Organización para la Cooperación y el Desarrollo Económico. (5 de enero de 2018). OCDE, mejores políticas para una vida mejor. Obtenido de https://www.oecd.org/centrodemexico/15aosde mexicoenlaocde.htm

Organización para la Cooperación y el Desarrollo Económico. (10 de enero de 2019). OCDE, mejores políticas para una vida mejor. Obtenido de 10 preguntas sobre BEPS: www.oecd.org/tax/beps.htm

Secretaría de Hacienda y Crédito Público. (30 de abril de 2019). Anexo III de la Resolución Miscelánea Fiscal para 2019. Criterios no vinculativos de las disposiciones fiscales. Diario Oficial de la Federación, págs. 1-36.
BÁRCENAS-PUENTE, José Luis \& ANDRADEOSEGUERA, Miguel Ángel. El proyecto BEPS y la planeación fiscal. Revista de Aplicaciones del Derecho. 2019 